\title{
Review of: "Observations of Boundary Layer Wind and Turbulence of a Landfalling Tropical Cyclone"
}

\author{
Zhiqiu Gao
}

Potential competing interests: The author(s) declared that no potential competing interests exist.

By using the observations from a 350-m tower, the paper analyzes the characteristics of wind profile, momemtum flux, TKE, vertical eddy diffusivity, and mixing length during the passage of Typhoon Mangkhut. In the observation period, the maximum 10-m wind was close to $20 \mathrm{~m} / \mathrm{s}$. The authors found that the height of the constant layer increased with the wind speed, and the drag coefficient and surface roughness were nearly invariant because the flux footprint was over land. Tower observations during tropical cyclone passage are limited, and the findings in this paper are valuable to the understanding of the tropical cyclone boundary layer.

Specific suggestions:

Line 36, have been -> were

Line 43, Cione et al., 2020 can be cited here

Cione, J. J., Bryan, G. H., Dobosy, R., Zhang, J. A., de Boer, G., Aksoy, A., Wadler, J. B., Kalina, E. A., Dahl, B. A., Ryan, K. and Neuhaus, J., 2020. Eye of the storm: Observing hurricanes with a small unmanned aircraft system. Bulletin of the American Meteorological Society, 101(2), pp.E186-E205.

Line 58, 'interact remain' -> 'interact with each other remains'

Figure 3, what does the direction 0 deree represent for?

Line 111 and line 133, the concluded $100 \mathrm{~m}$ and $40 \mathrm{~m}$ depth of surface layer contradict with each other. Figure $3 a$ and $5 \mathrm{a}$, in Figure $3 \mathrm{a}$, the $10-\mathrm{m}$ height wind can reach about $20 \mathrm{~m} / \mathrm{s}$, but in Figure $5 \mathrm{a}$, the maximum $10-\mathrm{m}$ height wind speed is only about $15 \mathrm{~m} / \mathrm{s}$.

Figure $5 \mathrm{a}$, I suggest using the 10-m height wind speed as the $\mathrm{x}$-axis, rather than the wind speed at the same height of the momentum flux. It would be more clear to distinguish the surface layer depth.

Figure 8 and 9, the data used should be from a period, not a moment (2018-09-16 07:30). 